\title{
POLÍTICAS E PRÁTICAS DE EDUCAÇÃo PATRIMONIAL no Brasil e na América do Sul: apresentação
}

Os processos de democratização política experimentados por diversos países da América do Sul, a partir da década de 1980, as novas formas de consumo e produção cultural, a globalização da economia e da cultura, as demandas por reconhecimento político das especificidades culturais de grupos e comunidades e as redefinições nos sentidos atribuídos ao patrimônio e às identidades em diversas escalas produziram um contexto favorável à recomposição da agenda social da cidadania e à reconstrução das pautas educacionais em variadas escalas.

No bojo dessas transformações, a educação patrimonial crescentemente tem ocupado espaço nas políticas e nos processos educacionais no Brasil e na América do Sul. Organizações internacionais, setores de Estado, instituições de ensino, museus, instituições culturais de natureza pública e privada ampliam suas intervenções nesse campo de ação, bem como, nos meios acadêmicos, há um progressivo interesse interdisciplinar em perscrutar as interfaces contemporâneas entre educação e patrimônio cultural. Adicione-se a tal diagnóstico um notável deslocamento na semântica dessas políticas, qual seja: de processos mono-identitários orientados pela consolidação da unidade nacional para processos multi-identitários orientados por processos de reconhecimento e novas atribuições valorativas à diversidade.

Nesse sentido, o presente dossiê visa apresentar artigos científicos que contribuam na elaboração de um diagnóstico ampliado sobre a educação patrimonial no Brasil e na América do Sul. A compilação apresenta produções escritas derivadas de investigações sistemáticas sobre o assunto e relatos e reflexões científicas oriundos de experiências institucionais relevantes para os referidos contextos nacionais. Em um momento de ampliação conceitual do debate sobre educação patrimonial, o conjunto dos artigos evidencia um mosaico de orientações teóricas e metodológicas. Para além da qualificada produção intelectual, esse dossiê objetiva ainda visibilizar e mobilizar uma rede de interlocuções acadêmicas de pesquisadores engajados em propostas de pesquisa ou sistematização de experiências no âmbito da educação patrimonial.

No primeiro artigo, Desafios para um nova Educação Patrimonial, Simone Scifone, ao constatar a inexistência de uma base teórica consistente para superar leituras mais tradicionais em seu campo de estudo, apresenta um conjunto de proposições teóricas com o objetivo de provocar a 
renovação do pensamento sobre educação patrimonial no Brasil. A autora busca refletir sobre os limites e as possibilidades das referidas ações em seu contexto nacional. Na sequência, ainda sobre a realidade brasileira, Rodrigo Manoel Dias da Silva parte da constatação de que, na atualidade, há uma ressignificação nos sentidos e nos usos sociopolíticos atribuídos aos patrimônios culturais, inscritos, com frequência, em uma ambivalência entre dinâmicas de desenvolvimento econômico e processos de afirmação identitária. No artigo "Narrativas identitárias e educação patrimonial no Brasil", o autor examina o estado atual da educação patrimonial no contexto de duas cidades brasileiras que sofreram processo de patrimonialização cultural.

O terceiro artigo, "Implementación y evaluación del Programa de Educación Patrimonial "PEPA", apresenta e discute uma das principais experiências em educação patrimonial no Chile, cuja denominação está enunciada em seu título. Neste, Gianina Sánchez Vega e Desiree Román Ponce caracterizam a ação promovida pelo Conselho de Monumentos Nacionais e, mediante utilização de investigação sistemática, analisam e avaliam a implementação do programa. No artigo "Experiencias de animación sociocultural y voluntariado impulsadas por el Programa Académico de Gestión Cultural en la Universidad de Piura - Peru”, Diana Aguirre Manrique expõe o projeto “Alma Tallán”, criado em 2013, como uma ferramenta de animação sociocultural para incentivar a participação da comunidade na salvaguarda do patrimônio local. Segundo a autora, a participação da população nas atividades culturais e nas proposições educacionais consolidam o patrimônio como um recurso para a coesão social e para novas formas de solidariedade.

Na continuidade, Bianca Vienni, David Barreiro e Camila Gianotti oferecem o artigo "Las redes de práctica como espacios educativos integrales: la red TRAMA3". O texto examina as contribuições da Rede de Ação Multivocal Arqueologia, Antropologia e Meio Ambiente (TRAMA3) no Uruguai, na qual o patrimônio ambiental é concebido como um eixo e como um campo transdisciplinar de pesquisa e de ação. O sexto artigo, "Aprendizaje dialógico y apropiación del patrimônio cultural: una educación patrimonial sostenida en hombros de gigantes", de Zaida García Valecillo, propõe uma abordagem para a educação patrimonial como ferramenta para a gestão do patrimônio cultural com base em teorias que enfatizam o diálogo, a apropriação social do patrimônio e seu posterior empoderamento. Para tal, revisa as contribuições de Paulo Freire, Jurgen Habermas e Ramón Flecha para uma rediscussão das concepções de educação patrimonial. Por fim, Carlos Rendón, no artigo “Algo en comúm”, discorre sobre questões patrimoniais, em perspectiva teórica. Segundo o autor, a cultura deve ser tratada como uma estratégia de diálogo entre arte e comunidade, consolidando uma concepção de ser humano, de suas experiências e de sua vida 
cotidiana. Essa reflexão parte da reflexão realizada na área de Museo y Territorios no Museo de Antioquia, na Colômbia.

A presente compilação intenciona contribuir, em suma, para a qualificação dos debates sobre educação patrimonial na América do Sul. Ao considerar abordagens múltiplas, o conjunto dos artigos procura evidenciar a superação das dicotomias que antagonizam as políticas e as práticas em Educação e destacar que as experiências em educação patrimonial se diversificam na mesma razão em são engendradas desde contextos de diversidade. Neste sentido, refutamos a ideia de celebração da diversidade, a qual, na maioria das situações que investigamos, apenas reiteram a mercantilização da memória, dos patrimônios e das formas simbólicas de viver. Tal simplificação faz-se obstáculo para a produção de políticas culturais alicerçadas na afirmação da convivência entre sujeitos e culturas diferentes. Em sociedades que se pretendam democráticas ou interculturais, refletir sobre educação patrimonial requer abordagens multidimensionais e atentas a seus desdobramentos históricos, sociopolíticos e culturais.

Boa leitura a todos!

Prof. Dr. Rodrigo Manoel Dias da Silva (Unisinos, Brasil) Profa. Dra. Zaida García Valecillo (UPEL, Venezuela)

Submetido em: Ago. 2016 Aprovado em: Dez. 2016 